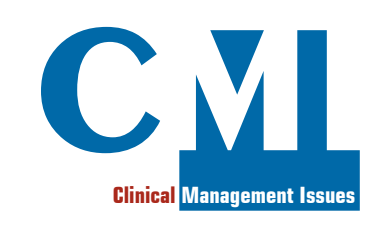

\title{
Editorial Staff Disclosure (2020)
}

Laura Fascio Pecetto is the Managing Editor of CMI journal. She declares she has no personal conflicts of interests. She works for SEEd Medical Publishers, that in 2020 has worked with AdRes Srl, Amgen Srl, ASST Fatebenefratelli Sacco, Biogen Italia Srl, Boehringer Ingelheim Italia s.p.a., CD Pharma Group Srl, CSL Behring Spa, Fondazione Charta, LinkHealth s.r.1. - Health Economics, Outcomes \& Epidemiology, NOPAIN ONLUS, Roche S.p.A., Swedish Orphan Biovitrum Srl, UCB Pharma S.p.A.

Rossella Iannone is Editor of CMI journal. She declares she has no personal conflicts of interests. She works for SEEd Medical Publishers, that in 2020 has worked with AdRes Srl, Amgen Srl, ASST Fatebenefratelli Sacco, Biogen Italia Srl, Boehringer Ingelheim Italia s.p.a., CD Pharma Group Srl, CSL Behring Spa, Fondazione Charta, LinkHealth s.r.l. - Health Economics, Outcomes \& Epidemiology, NOPAIN ONLUS, Roche S.p.A., Swedish Orphan Biovitrum Srl, UCB Pharma S.p.A.

Enzo Cappelluti is the Layout Editor of CMI journal. He declares he has no personal conflicts of interests. He works for SEEd Medical Publishers, that in 2020 has worked with AdRes Srl, Amgen Srl, ASST Fatebenefratelli Sacco, Biogen Italia Srl, Boehringer Ingelheim Italia s.p.a., CD Pharma Group Srl, CSL Behring Spa, Fondazione Charta, LinkHealth s.r.l. - Health Economics, Outcomes \& Epidemiology, NOPAIN ONLUS, Roche S.p.A., Swedish Orphan Biovitrum Srl, UCB Pharma S.p.A. 